Bull. Mater. Sci., Vol. 7, No. 5, December 1985, pp. 475-481. (C) Printed in India.

\title{
Hydrothermal transformation of clinoptilolite
}

\author{
M S JOSHI* and V V JOSHI \\ Department of Physics, Sardar Patel University, Vallabh Vidyanagar 388 120, India
}

MS received 11 August 1984; revised 22 July 1985

\begin{abstract}
Procedure for hydrothermal transformation of natural clinoptilolite at $160^{\circ} \mathrm{C}$ is described. The synthesis is carried out in the system $\mathrm{Na}_{2} \mathrm{O}-\mathrm{Al}_{2} \mathrm{O}_{3}-\mathrm{SiO}_{2}-\mathrm{H}_{2} \mathrm{O}$. Products of 24-168 hr runs are characterized by $\mathrm{x}$-ray diffraction, IR spectroscopy, energy dispersive analysis of $x$-rays (EDAx), and electron microscopy. Presence of analcime-type and faujasitetype zeolites in the final products is established. Si/Al ratio of the final mixed phase is estimated as 2.91. Spheroid crystals of analcime, fibrous crystals of mordenite (on analcime), and well developed polyhedral crystals of analcime-faujasite mixed phase are illustrated and described. It is shown that crystals grow by two-dimensional nucleation mechanism.
\end{abstract}

Keywords. Zeolite; analcime; faujasite; mordenite; polyhedral.

\section{Introduction}

There are several minerals which are not directly usable in their native form. However, there is ample scope for converting them to more useful materials. Synthesis of more useful forms of zeolites, having scientific and industrial applications, has drawn the attention of several research workers all over the world. The hydrothermal method is principally used for zeolite synthesis and several successful attempts have been made in this laboratory. Choudhari (1983, has effected transformation of (i) calcined scolecite into synthetic analogues of analcime crystals of spheroid and cubic morphologies and (ii) calcined stilbite into synthetic analcime type crystals of habits like needles, spheroids and prisms. Choudhari (1983) also transformed mineral clay into polyhedral (euhedral) analcime-type, mordenite-type acicular needle and erionite-type bunched needle crystals. These two investigations were carried out at $180^{\circ}$ and $160^{\circ} \mathrm{C}$ respectively, and at autogenous pressure. Similar experiments have also been successfully carried out on the transformation of mesolite. In this laboratory Joshi et al (1982a, b, 1983) have grown vzs-1, 2, 3 and 4 zeolites by the hydrothermal method. Recently, we have also succeeded in synthesizing zSM-5 and ZSM-8 type zeolites. Robson and Riley (1977) have reported that hecter clinoptilolite, when treated with sodium hydroxide, forms faujasite. Sudo and Matsuoka (1959) treated volcanic glass with sodium hydroxide and obtained sodalite and faujasite. Conversions of clinoptilolite and mordenite to faujasite-type and p-type zeolites have been reported by Miyata and Okazaki (1970). Negishi and Nakamura (1970) treated clinoptilolite with $\mathrm{NaOH}-\mathrm{NaCl}$ solution at $100^{\circ} \mathrm{C}$ and observed the conversion sequence clinoptilolite $\rightarrow$ amorphous material $\rightarrow x$ type zeolite $\rightarrow$ sodalite. The present paper reports observations and results of our attempts to transform natural clinoptilolite by the hydrothermal method.

\footnotetext{
* To whom all correspondence should be addressed.
} 


\section{Experimental details}

Clinoptilolite used in the present investigation was rich in calcium and had a Si/Al ratio of 3.6. Powdered clinoptilolite was calcined at $700^{\circ} \mathrm{C}$ for twelve hours. Structural collapse thus effected was ascertained with the help of $x$-ray diffraction. Chemical composition was determined by energy dispersive analysis of $\mathrm{x}$-rays (EDAX). Calcined clinoptilolite, sodium hydroxide and aluminium hydroxide were taken in the ratio $4: 2: 1$ by weight with excess of double distilled water. Tetrapropylammonium hydroxide was used as a base during crystallization. The resulting gelling mixture had a $\mathrm{pH}$ of 11.5. This mixture was transferred to the Berghof autoclave, which is made up of special stainless steel (type DIN 1.4571) having poly tetra fluoro ethylene (PTFE) interchangeable liners. It can be used upto a maximum working temperature of $250^{\circ} \mathrm{C}$, for an indefinite period of time. The temperature can be measured with the help of the $\mathrm{Ni}-\mathrm{Cr}-\mathrm{Ni}$ thermosensor which is fixed at the centre of the autoclave. The temperature is regulated by a thermostatically controlled heating circuit with an accuracy of $\pm 5^{\circ} \mathrm{C}$. Temperature regulation operates only when the thermosensor is connected. There is a hollow cylindrical shaft with stirrer wings which can be rotated electrically at the desired speed. Stirring ensures homogeneity of the gelling mixture. Pressure is measured by a manometer pressure gauge fixed in the lid. The pressure in our experiments was $1000 \mathrm{psi}$, with a rupture disc to ensure that the pressure does not exceed the limit of the autoclave. In the present investigation crystallization was carried out at $160^{\circ} \mathrm{C}$. Runs of duration ranging from 24 to $168 \mathrm{hrs}$ were tried. The product obtained at the end of each run was repeatedly washed with double distilled water, and then dried in an electrical oven at $110^{\circ} \mathrm{C}$. Each product was then characterized with the help of x-ray diffraction, IR spectroscopy and EDAX were done. Morphology of the crystals grown was examined by a scanning electron microscope.

\section{$2.1 X$-ray powder analysis}

Observed $d$ values for the final product, with the relative intensities, are given in table 1 . $\mathrm{X}$-ray analysis shows that the synthetic product contains analcime and faujasite as the main phases.

\subsection{Infrared spectral analysis}

Infrared spectra of the synthesized products were recorded with the help of a Perkin Elmer 180 model using $\mathrm{KBr}$ pellets. In these spectra characteristic sorption bands of the zeolite family were detected. Assignment of the infrared bands as per Flanigen et al (1971) for the final product is given in table 2.

\subsection{Chemical analysis}

Results of chemical analysis by EDAX, for the product obtained at the end of a $168 \mathrm{hr}$ run, are shown in table 3. The Si/Al ratio for this product, which is the mixed phase of sodium analcime and sodium faujasite, is found to be $2 \cdot 91$.

\subsection{Study of morphology by SEM}

Each sample (at the end of each growth run) was examined under a scanning electron 
Table 1. X-ray powder data for clinoptilolite transformation; $168 \mathrm{hr}$ run

\begin{tabular}{lrl}
\hline$d$ A & $I / I_{0}$ & Phase \\
\hline 5.5912 & 94 & $a, f$ \\
4.8216 & 28 & $a, f$ \\
3.6479 & 14 & $f$ \\
3.4076 & 100 & $a, f$ \\
2.9214 & 79 & $a, f$ \\
2.7968 & 13 & $a, f$ \\
2.6827 & 28 & $a, f$ \\
2.498 & 24 & $a, f$ \\
2.420 & 13 & $a$ \\
2.3559 & 32 & - \\
2.222 & 15 & $a$ \\
2.1659 & 5 & $a$ \\
$2 .(4403$ & 13 & $a$ \\
2.0230 & 7 & $a$ \\
1.9028 & 20 & $a$ \\
1.8661 & 13 & $a$ \\
1.7399 & 25 & $a$ \\
1.7142 & 10 & $a$ \\
1.7098 & 10 & - \\
1.6865 & 10 & $a$ \\
1.6639 & 10 & $a$ \\
1.6156 & 10 & $a$ \\
1.5951 & 10 & $a$ \\
1.4796 & 7 & $a$ \\
1.4447 & 9 & - \\
1.4135 & 10 & $a$ \\
1.3576 & 13 & - \\
\hline & & \\
$a$ & & \\
& 10 & \\
\end{tabular}

$a$ - analcime; $f$-faujasite

microscope. Crystals obtained at the end of a $48 \mathrm{hr}$ run are shown in figure 1. Mostly spheroid analcime crystals are obtained. Fibrous crystals of mordenite, grown over analcime spheroid crystals, are also seen in this SEM. Figure 2 shows crystals obtained at the end of a $72 \mathrm{hr}$ run. Well developed polyhedral and platy crystals are obtained. The latter exhibit growth layers. From these observations it is suggested that crystals grow by two dimensional spreading and piling of growth layers. Well developed crystals of a mixed phase of sodium analcime and sodium faujasite are illustrated in figure 3, also an SEM (growth run $144 \mathrm{hr}$ ). Two polyhedral, well developed, analcime-type crystals are shown in figure 4 (growth run $168 \mathrm{hr}$ ).

\section{Discussion}

Transformation of clinoptilolite has been effected to more important phases, sodium analcime and sodium faujasite zeolites. The reacting gel mixture contains sodium and 
Table 2. Infrared spectral assignment -clinoptilolite transformation; $168 \mathrm{hr}$

\begin{tabular}{lc}
\hline Vibrational mode & Frequency $\mathrm{cm}^{-1}$ \\
\hline $\begin{array}{l}\text { A. Structure sensitive } \\
\text { (external linkages) }\end{array}$ & \\
Double ring (SBU) & \\
$650-500$ & $520 \mathrm{sh}$ \\
Pore opening & $360 \mathrm{wsh}$ \\
$420-300$ & $390 \mathrm{wsh}$ \\
Symmetric stretch & \\
$750-820$ & $790 \mathrm{w}$ \\
Asymmetric stretch & \\
$1150-1050$ & $1130 \mathrm{sh}$ \\
Structure insensitive & \\
(internal tetrahedron) & \\
Asymmetric stretch & \\
$1250-950$ & $1100 \mathrm{~b}$ \\
Symmetric stretch & \\
$750-650$ & $700 \mathrm{~b}$ \\
T-O bend & $470 \mathrm{~b}$ \\
$500-420$ & $1650 \mathrm{~s}$ \\
H 2 O bend & $3480 \mathrm{sb}$ \\
OH stretch & \\
\hline
\end{tabular}

sh-shoulder; wsh-weak shoulder; $w$ - weak; $b$-broad; $s b$-strong broad; $s-$ strong

Table 3. Chemical analysis of clinoptilolite transformation; $168 \mathrm{hr}$ run (EDAX)

\begin{tabular}{ccccc}
\hline Element & $\begin{array}{c}\text { Weight \% } \\
\text { (element) }\end{array}$ & $\begin{array}{c}\text { Weight } \% \\
\text { (oxide) }\end{array}$ & $\begin{array}{c}\text { Atomic \% } \\
\text { (element) }\end{array}$ & $\begin{array}{c}\text { Atomic \% } \\
\text { (oxide) }\end{array}$ \\
\hline $\mathrm{Na}$ & 6.025 & 8.122 & 5.282 & 7.923 \\
$\mathrm{Al}$ & 10.971 & 20.730 & 8.195 & 20.486 \\
$\mathrm{Si}$ & 33.257 & 71.148 & 23.864 & 71.591 \\
\hline
\end{tabular}

$\mathrm{Si} / \mathrm{Al}=2.91(\mathrm{mixed}$ phase of sodium analcime and sodium faujasite)

calcium ions with tetrapropylammonium hydroxide as an organic base. Synthesis was carried out in the system $\mathrm{Na}_{2} \mathrm{O}-\mathrm{Al}_{2} \mathrm{O}_{3}-\mathrm{SiO}_{2}-\mathrm{H}_{2} \mathrm{O}$. Calcium ions are also present in the reacting gel. Crystallization of the reaction mixture could be in the system $\mathrm{Ca}_{2} \mathrm{O}-\mathrm{Al}_{2} \mathrm{O}_{3}-\mathrm{SiO}_{2}-\mathrm{H}_{2} \mathrm{O}$ or in the mixed system of calcium and sodium. Crystallization of calcium aluminosilicate gels requires a temperature of $275^{\circ} \mathrm{C}$ and about four weeks time. In the present investigation the temperature was $160^{\circ} \mathrm{C}$ and, the maximum time of growth was $168 \mathrm{hr}$. Under these conditions crystallization in calcium system is not possible. Barrer and Denny (1961) have synthesized Ca-D, Ca-I, Ca-J zeolites and, found that no significant crystallization of a zeolite phase in calcium system can occur below $225^{\circ} \mathrm{C}$. It is inferred that calcium ions have not taken part in the crystallization, since the temperature was low. In the present case, sodium aluminosilicate gel alone has crystallized. Crystallinity was poor for growth runs below $72 \mathrm{hr}$. The induction period for crystallization was $24 \mathrm{hr}$. Crystallinity was better for crystals obtained from a $144 \mathrm{hr}$ run, while good crystals were secured from growth runs of $168 \mathrm{hr}$. 


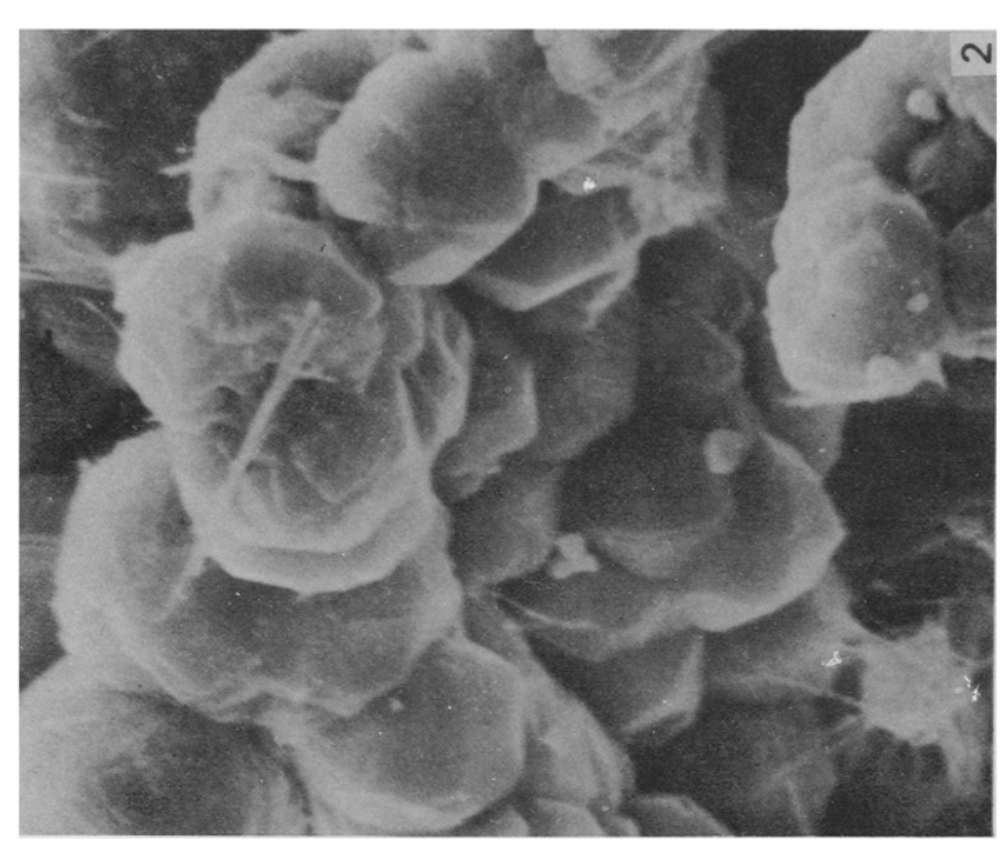

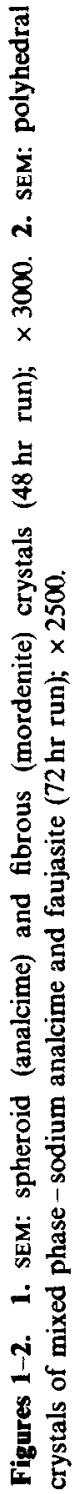

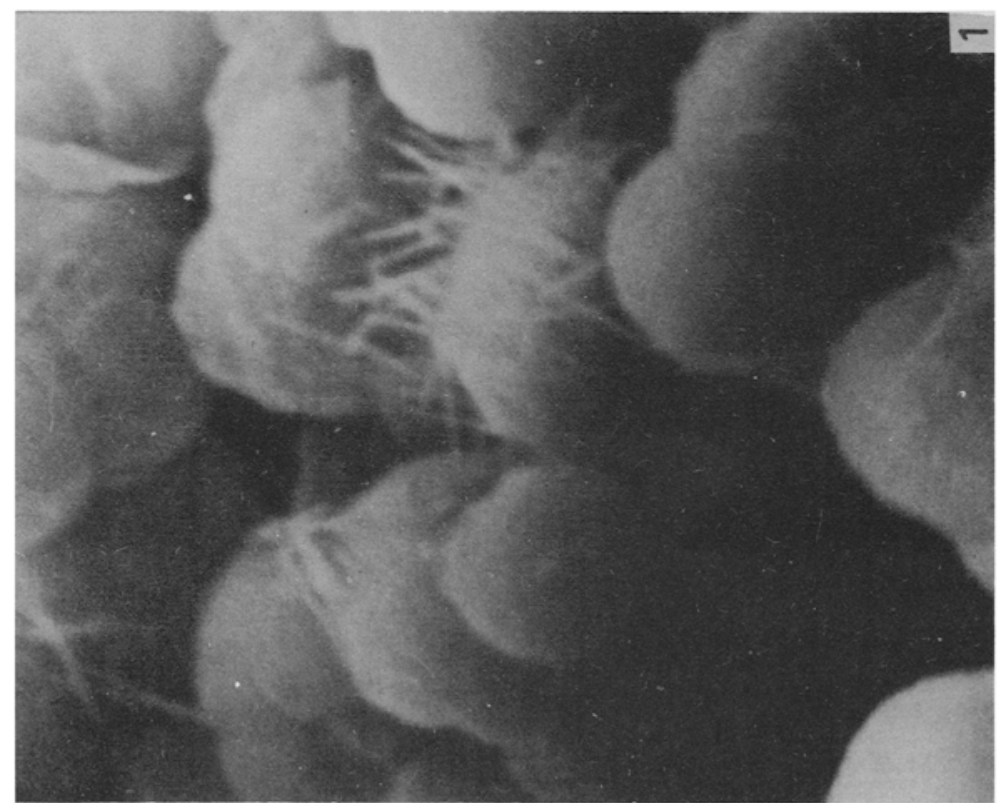




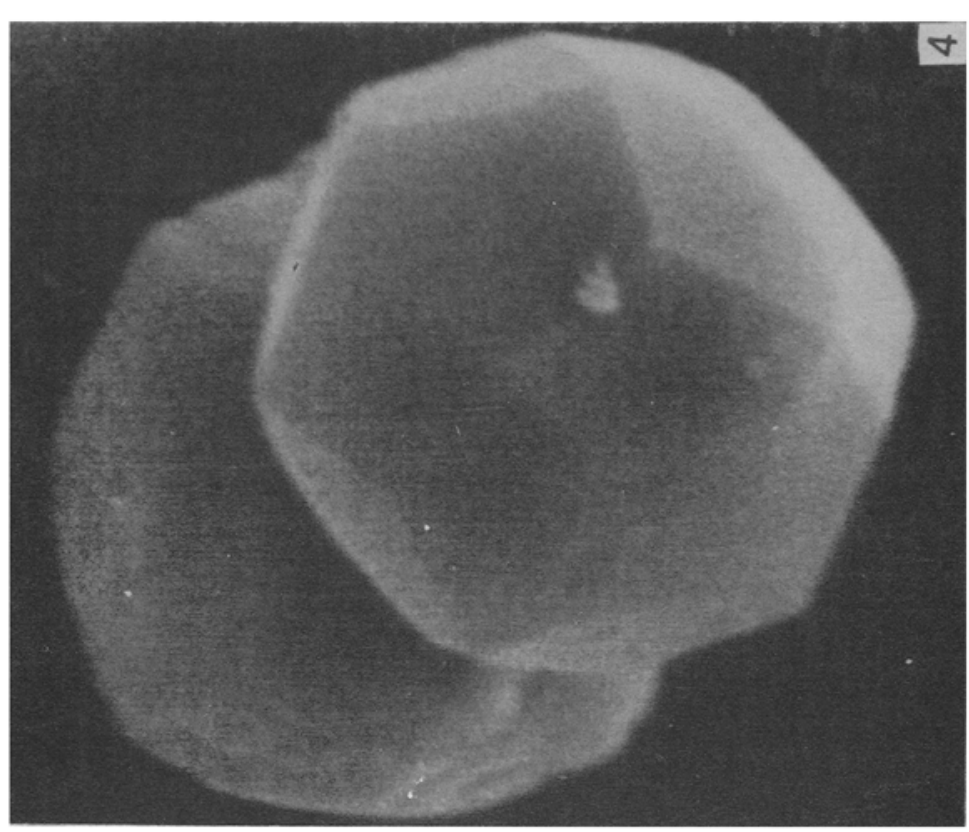

$\underset{8}{8}$

产

$\exists$

?ํㅗㅇ

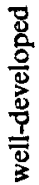

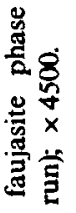

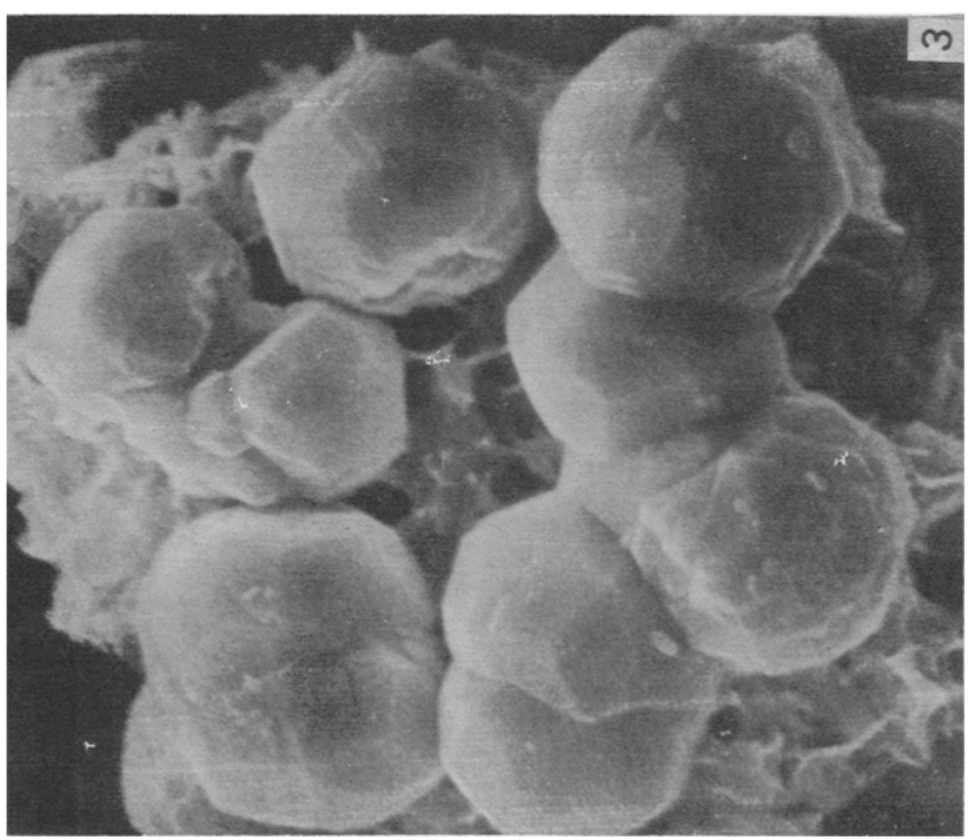

토

귱용

흘 를

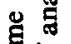

븡

密

客

寻

흠

㤐总

का

I 3

害罟

is 


\section{Conclusions}

The presence of tetrapropylammonium hydroxide influences the morphology of crystals grown, more useful phases being produced. Crystals grow by a two dimensional growth mechanism.

\section{Acknowledgements}

vvj is grateful to the UGC India for a fellowship. He is thankful to the Principal, Science College, Nanded for encouragement.

\section{References}

Barrer R M and Denny D J 1961 J. Chem. Soc. 983

Choudhari A L 1983 Studies on physico-chemical properties of natural scolecite and stilbite, and synthesis of some zeolites by hydrothermal method Ph.D. thesis, Sardar Patel University, Vallabh Vidyanagar

Flanigen E M, Khatami H and Szymansky H A 1971 Molecular Sieve Zeolites (Washington D.C.: American Chemical Society) 1201

Joshi M S, Choudhari A L and Kanitkar R G 1983 Cryst. Res. Technol. 181347

Joshi M S, Rao Mohan P, Choudhari A L and Kanitkar R G 1982a Cryst. Res. Technol. 17925

Joshi M S, Rao Mohan P, Choudhari A L and Kanitkar R G 1982b J. Mater. Sci. Lett. 1195

Miyata Y and Okazaki S 1970 Kogyo Koyaku Zasshi 731940

Negishi T and Nakamura H 1970 Kobustugaku Zasshi 1072

Robson H E and Riley L K 1977 Molecular Sieves II. Amer. Chem. Soc. Symp. Ser. 40233

Sudo T and Matsuoka M 1959 Geochim. Cosmochim. Acta 171 